\title{
Consumer-based strategy: using multiple methods to generate consumer insights that inform strategy
}

\author{
Rebecca Hamilton ${ }^{1}$
}

Published online: 22 February 2016

(C) Academy of Marketing Science 2016

As the field of marketing has expanded and matured, it is natural to observe more methodological specialization among researchers. Methodological proficiency-whether in econometrics, analytical modeling, experimental design, or ethnography - is critical for publishing in top journals but takes years to develop. One of the consequences highlighted by panel discussions at several recent conferences (e.g., "Marketing as a Field: Are We Progressing or Losing our Cohesiveness?" at Summer AMA 2014) is the increasing division of the field based on methodology. Doctoral students are specializing earlier, and researchers who use different methods are attending fewer joint conferences. Yet the complex problems we are trying to solve as a field often demand multi-method investigation, whether via researchers building on earlier work using different methods or collaborating on a multi-method paper. For example, our understanding of when and why consumers engage in positive and negative word of mouth will certainly be richer if we integrate insights from empirical analyses of online data, experimental manipulations of product experiences, and qualitative research examining online communities.

Here is where we have an opportunity: defining specializations within the field of marketing not by methodology but by unit of analysis (consumers, firms, or markets) can help marketing researchers harness the power of multiple methods. In this editorial, I will define one such specialization: consumerbased strategy.

Rebecca Hamilton

Rebecca.Hamilton@georgetown.edu

1 McDonough School of Business, Georgetown University, 537 Rafik Hariri Building, Washington, DC 20007, USA

\section{What is consumer-based strategy?}

Consumer-based strategy is organizational strategy that is developed based on insights about consumers. Such strategy can be developed based on understanding consumers' wants and needs (e.g., Lam et al. 2013; Olson 2013), the costs consumers incur to purchase and own goods and services (e.g., Choi et al. 2014; Zielke and Komor 2015), the convenience of obtaining goods and services (e.g., Baker and Wakefield 2012; Lim et al. 2015), or what makes communication between the organization and the consumer more effective (e.g., Brasel and Gips 2014; Mikolon et al. 2015). All of these insights share a focus on consumers as the unit of analysis: data about needs, costs of purchase and ownership, convenience, and communication effectiveness can be collected for each consumer.

Consumer-based strategy can be contrasted with strategy developed based on an understanding of firm-level variables such as organizational capabilities (e.g., Angulo-Ruiz et al. 2014; Krush et al. 2015) or supply chain relationships (e.g., Kauferle and Reinartz 2015; Scheer and Miao 2010). It can also be contrasted with organizational strategy that responds to market-level variables such as market size and market growth.

Users of consumer-based strategy may include for-profit firms (e.g., Brasel and Gips 2014; Brocato et al. 2015), nonprofits (e.g., Pappu and Cornwell 2014), and governmental bodies (e.g., Burton et al. 2015; Lwin et al. 2007). Firms may wish to persuade consumers to purchase their products and services; generating consumer insights can help them develop the right products and services for the right prices and effectively persuade consumers to buy them. Non-profits may have goals to convince consumers to donate to their charitable causes or to understand how their partnerships with for-profit firms will affect consumers' perceptions of their organizations. Finally, governmental bodies may want to nudge 
consumers to improve their own welfare or the welfare of other consumers.

How does consumer-based strategy differ from consumer research? The goal of consumer research is to generate consumer insights; consumer-based strategy takes the next step of leveraging these consumer insights to develop organizational strategy. For example, in their research examining consumers' reactions to green and non-green corporate actions, Xie et al. (2015) measure the effects of corporate actions on affective measures such as gratitude and anger as well as managerially relevant dependent variables such as consumers' intentions to engage in positive or negative word of mouth. These affective process measures help the researchers understand when and why consumers engage in word of mouth (consumer insights). The use of process measures and managerially relevant dependent measures to inform a detailed discussion of managerial implications makes this paper a good fit for the Journal of the Academy of Marketing Science (JAMS).

The term consumer-based strategy deliberately highlights consumer-rather than customer - insights. Consumers is a more general term; customers have a relationship with a specific organization. This difference is important for two reasons. First, when developing marketing strategy, it is important to predict how non-customers as well as customers will respond. Second, the goal of JAMS is to build theory that can be applied across organizations. Consumer insights generate consumer-based strategy, which can be applied by managers to improve their customer relationships. For example, a recent paper published by Lim et al. (2015) reports a series of experimental studies examining how consumers react to accelerating or decelerating progress while waiting for services. These studies were conducted in a variety of contexts, illustrating the generality of the effects. In one study, participants were told to act as if they were waiting in line for an ATM machine, and their progress (manipulated using confederates standing in front of them) was either accelerated or decelerated; perceived wait time was measured. In another study, progress was manipulated in calls to a travel agent's customer service line, and participants evaluated the wait time they experienced. In a third study, participants evaluated wait times after watching videos of customers being served in a restaurant. Finally, in a field study conducted in a fashion boutique, the time to accomplish various tasks (getting a requested size, waiting for the fitting room, making a payment) was manipulated so that it was either accelerated relative to expectations or decelerated; again, perceived wait time was measured. Across these contexts, whether participants were waiting for an ATM machine or for a call to be answered, the authors show that accelerating and decelerating wait times have systematic and measurable effects on consumers' perceived wait times. Notably, due to both primacy and recency effects, a fast-slow-fast progress sequence yielded the shortest perceived wait times. Such general consumer insights about wait times can be leveraged by managers who want to manage the perceived speed of their own customer service encounters - regardless of industry - to maximize the satisfaction of their customers.

\section{What research methods does consumer-based strategy leverage?}

A variety of research methods can be used to generate consumer insights. What they all have in common is that they can be used to generate data at the consumer level. Observational data (such as publicly available online data; Hennig-Thurau et al. 2015; Thompson et al. 2015), experiments (Heidenreich et al. 2015; Xie et al. 2015), surveys (Brocato et al. 2015; Gallan et al. 2013), customer purchase data (Carter and Curry 2013; Papies et al. 2011), and qualitative data (Leigh et al. 2006; Lemke et al. 2011) can be used to generate consumer insights. An easy "litmus test" is whether each row in one's dataset represents a consumer (as opposed to a firm or a market).

Because consumer-based strategy researchers share an interest in the consumer as the unit of analysis, this classification can connect researchers who use different methods, whether this is at conferences organized to examine substantive areas of interest, in special issues of journals, or in centers or departments within business schools. For example, the Marketing Area at Georgetown's McDonough School of Business has positioned itself to focus on consumers as the unit of analysis, screening potential hires as well as new initiatives based on this focus. The goal of this positioning is to facilitate research conversations and collaborations among researchers with different methodological expertise via their common interest in consumers. Researchers can unite to solve problems while applying different methods to generate consumer insights; because they share an interest in consumers as the unit of analysis, consumer-based strategy researchers can better appreciate the strategic implications of research conducted using different methods.

\section{Where is consumer-based strategy research published?}

Although researchers may not immediately think of JAMS as an outlet for consumer research, an analysis of articles published in JAMS over the past 10 years (volume 34, issue 1, through volume 43 , issue 6 ) shows that $35 \%$ of the these articles have leveraged consumer insights to generate strategic recommendations (see Table 1). Of these articles, $45 \%$ generate consumer insights using experiments, $35 \%$ via surveys, and $10 \%$ via empirical data (e.g., publicly available online data, consumer purchase data). With over a third of its pages in recent years devoted to consumer-based strategy, JAMS seems to be a welcoming outlet for research that generates 
Table 1 Articles published in JAMS from 2006 to 2015

\begin{tabular}{|c|c|c|c|c|c|c|c|}
\hline & Experiments & Surveys & Qualitative & Empirical & Methods & Conceptual & Total \\
\hline Consumer as unit of analysis $(n=163)$ & $45 \%$ & $35 \%$ & $9 \%$ & $10 \%$ & $0 \%$ & $4 \%{ }^{\mathrm{a}}$ & $35 \%$ \\
\hline Firm as unit of analysis $(n=228)$ & $7 \%$ & $44 \%$ & $10 \%$ & $27 \%$ & $1 \%$ & $18 \%^{\mathrm{a}}$ & $50 \%$ \\
\hline $\operatorname{Total}(N=468)^{\mathrm{b}}$ & $20 \%$ & $37 \%$ & $10 \%$ & $18 \%$ & $2 \%$ & $13 \%$ & $100 \%$ \\
\hline
\end{tabular}

${ }^{\text {a }}$ Total across methods sums to more than 100 because some articles use multiple methods

${ }^{b}$ Total is greater than the sum of the first two rows because some articles examined multiple perspectives or could not be classified as one or the other (e.g., methods papers)

consumer insights to inform strategy, regardless of the methodological paradigm used.

An important benefit of publishing consumer-based strategy research in JAMS is that researchers who use multiple methods will be exposed to the research. The same analysis of articles published in JAMS over the last 10 years shows that the articles - whether they focus on consumer-based strategy or firm-based strategy - leverage many different methods: $20 \%$ of articles reported the results of experiments and $37 \%$ the results of surveys, $18 \%$ used empirical data, and $10 \%$ reported qualitative data (Table 1; another $16 \%$ of the articles were conceptual papers, 2 were editorials, and 3 were introductions to special issues, book reviews, and other announcements). Readers of JAMS are united not by methodology but by an interest in the link between scholarly research and practice.

\section{What are the advantages of consumer-based strategy as a classification?}

Marketing strategy questions are challenging, and generating relevant insight may require multiple methods. Unfortunately, dividing journals and conferences based upon methods used by researchers may not foster knowledge sharing among researchers who use quantitative versus qualitative versus experimental research methods. The alternative classification proposed here distinguishes between questions that can be answered by generating insights that focus on consumers as the unit of analysis and those that focus on the firms or on markets as the unit of analysis.

Questions that focus on the consumer as the unit of analysis are at the interface between firms and consumers, including those geared toward understanding consumer wants and needs, the costs and benefits consumers perceive when acquiring, obtaining, and maintaining goods and services, and what makes communications between organizations and consumers effective. There are three essential components of consumerbased strategy research:

- Strategic recommendations are based upon consumer insights.
- Consumer insights are not specific to a firm or to a consumption context; they can be generalized across firms and contexts.

- Regardless of the method used, the consumer (rather than the firm) is the unit of analysis.

Using multiple methods within a paper is challenging, and only a small percentage of the articles published over the past 10 years in JAMS have used multiple methods. However, a much larger percentage of these articles cite research that is based on insights generated using a different method. This suggests that fostering conversations about consumer-based strategy has the potential to leverage insights across methodologies. Conference sessions can be planned to focus on substantive questions that unite consumer-based strategy researchers across the methods in which they are expert. For example, discussions about what makes online advertising successful might combine insights from experimental research with empirical analysis of online clicks. Discussions about consumer loyalty might leverage insights from interviews with consumers as well as a consumer-level data from a loyalty program member database. To this end, JAMS will be hosting a conference on consumer-based strategy in 2017 and publishing a special issue on consumer-based strategy.

\section{How should writing consumer-based strategy papers be approached?}

Can any research that focuses on consumers as the unit of analysis provide the basis for a consumer-based strategy paper? Not all research focusing on consumers will be a good fit. First, the phenomenon being studied must be of interest to organizations, whether these are for-profit firms, non-profits, or governmental agencies. For example, Brasel and Gips (2014) compared consumers' reactions to advertisements with and without same-language subtitles; this is relevant to managers because organizations have choices to make about the format of the advertisements they place. Second, the dependent variables that are measured must be relevant to decision makers within these organizations. Brasel and Gips (2014) measured consumers' intentions to learn more about and to 
use the brands featured in the advertisements they viewed as well as verbal and visual recall of the ad content. Finally, it is essential that the insights derived apply to a range of contexts; the insights should be general to consumers instead of specific to one organization's customers. Brasel and Gips (2014) conducted a series of four experimental studies using a variety of advertisements for different brands and compared their dependent measures across advertisements. They also used multiple methods, including both eye tracking and more traditional self-report measures. This allows the authors to draw relatively general conclusions about consumer reactions to advertisements with and without subtitles.

One common problem we observe among papers submitted to JAMS is that although they convey new insights about consumers, it is not clear how these consumer insights are relevant to decision makers within organizations. For example, a set of lab experiments might shed new light on consumer information processing by having participants react to abstract stimuli. Taking the next step of identifying decision makers for whom these insights are relevant can help the authors transform these insights into a consumer-based strategy paper. Do the insights have implications for consumers who are learning about new products, for consumers making decisions while shopping online, or for the way consumers interpret prices presented in different formats? The most successful consumer-based strategy papers highlight organizational implications in their introductory sections, citing relevant research on consumer perceptions of new products, online shopping, or pricing, instead of discussing strategic implications only as an afterthought. Following initial studies with follow-up studies in which stimuli more closely mirror decision making contexts and measuring organizationally relevant dependent variables will also help readers make the connection between basic consumer insights and organizational strategy. Successful consumer-based strategy papers connect novel insights about consumers to actions and dependent variables that are relevant to decision makers within organizations.

Another common problem we observe among submissions is that the consumer insights may be specific to one organization or set of consumers. If only one study or survey is conducted, data from only one company is collected, or only one group of consumers is observed, then authors should think carefully about the degree to which their insights are likely to generalize to other consumers in different settings. One solution is to collect more data. However, if it is difficult or prohibitively expensive to obtain additional primary data, secondary data may provide useful benchmarks. Referencing published research conducted with other consumers in different settings may help the authors identify variables that are unique to their setting or common across organizations. Comparisons with publicly available data, such as industrylevel purchase data or statistics about online shopping, may help readers see that findings specific to one set of consumers or one context are likely to generalize. Successful consumer- based strategy papers help decision makers within organizations know when the insights should apply to their own customers and settings and when they will not.

To improve the chances of a consumer-based strategy paper's success in the review process at JAMS, authors might consider the following checklist:

- Is the phenomenon being studied of interest to organizations, whether these are for-profit firms, non-profits, or governmental agencies? Does the positioning of the paper highlight its relevance to these organizations?

- Are the dependent variables in at least one study relevant to decision makers within organizations?

- Can decision makers influence the independent variables or moderating variables being examined, making the insights actionable?

In summary, focusing on consumers as the unit of analysis and combining insights generated via multiple methods to inform strategy offers high potential for knowledge building within the field of marketing. As a classification, consumerbased strategy can help to unite researchers motivated by a common interest in consumers, and historical data suggests that JAMS is a receptive outlet for this research. Following a few simple steps for designing and positioning research that focuses on consumers as the unit of analysis will help authors write successful consumer-based strategy papers.

\section{References}

Angulo-Ruiz, F., Donthu, N., Prior, D., \& Rialp, J. (2014). The financial contribution of customer-oriented marketing capability. Journal of the Academy of Marketing Science, 42(4), 380-399.

Baker, J., \& Wakefield, K. (2012). How consumer shopping orientation influences perceived crowding, excitement, and stress at the mall. Journal of the Academy of Marketing Science, 40(6), 761-806.

Brasel, S. A., \& Gips, J. (2014). Enhancing television advertising: samelanguage subtitles can improve brand recall, verbal memory, and behavioral intent. Journal of the Academy of Marketing Science, 42(3), 322-336.

Brocato, E. D., Baker, J., \& Voorhees, C. M. (2015). Creating consumer attachment to retail service firms through sense of place. Journal of the Academy of Marketing Science, 43(2), 200-220.

Burton, S., Cook, L. A., Howlett, E., \& Newman, C. L. (2015). Broken halos and shattered horns: overcoming the biasing effects of prior expectations through objective information disclosure. Journal of the Academy of Marketing Science, 43(2), 240-256.

Carter, R. E., \& Curry, D. J. (2013). Perceptions vs. performance when managing extensions: new evidence about the role of fit between a parent brand and an extensions. Journal of the Academy of Marketing Science, 41(2), 253-269.

Choi, J., Li, Y. J., Rangan, P., Chatterjee, P., \& Singh, S. (2014). The oddending price justification effect: the influence of price endings on hedonic and utilitarian consumption. Journal of the Academy of Marketing Science, 42(5), 545-557. 
Gallan, A. J., Jarvis, C. B., Brown, S. W., \& Bitner, M. J. (2013). Customer positivity and participation in services: an empirical test in a health care context. Journal of the Academy of Marketing Science, 41(3), 338-356.

Heidenreich, S., Wittkowski, K., Handrich, M., \& Falk, T. (2015). The dark side of customer co-creation: exploring the consequences of failed co-created services. Journal of the Academy of Marketing Science, 43(3), 279-296.

Hennig-Thurau, T., Wiertz, C., \& Feldhaus, F. (2015). Does Twitter matter? The impact of microblogging word of mouth on consumers' adoption of new movies. Journal of the Academy of Marketing Science, 43(3), 375-394.

Kauferle, M., \& Reinartz, W. (2015). Distributing through multiple channels in industrial wholesaling: how many and how much? Journal of the Academy of Marketing Science, 43(6), 746-767.

Krush, M. T., Sohi, R. S., \& Saini, A. (2015). Dispersion of marketing capabilities: impact on marketing's influence and business unit outcomes. Journal of the Academy of Marketing Science, 43(1), 32-51.

Lam, S. K., Ahearne, M., Mullins, R., Hayati, B., \& Schillewaert, N. (2013). Exploring the dynamics of antecedents to consumers- brand identification with a new brand. Journal of the Academy of Marketing Science, 41(2), 234-252.

Leigh, T. W., Peters, C., \& Shelton, J. (2006). The consumer quest for authenticity: the multiplicity of meanings within the MG subculture of consumption. Journal of the Academy of Marketing Science, 34(4), 481-493.

Lemke, F., Clark, M., \& Wilson, H. (2011). Customer experience quality: an exploration in business and consumer contexts using repertory grid technique. Journal of the Academy of Marketing Science, 39(6), 846-869.

Lim, E. A. C., Kum, D., \& Lee, Y. H. (2015). Understanding how changes within service experiences impact prospective vs. retrospective time judgements. Journal of the Academy of Marketing Science, 43(6), 730-745.

Lwin, M., Wirtz, J., \& Williams, J. D. (2007). Consumer online privacy concerns and responses: a power-responsibility equilibrium perspective. Journal of the Academy of Marketing Science, 35(4), 572-585.

Mikolon, S., Quaiser, B., \& Weiseke, J. (2015). Don’t try harder: using customer inoculation to build resistance against service failures. Journal of the Academy of Marketing Science, 43(4), 512-527.

Olson, E. (2013). It's not easy being green: the effects of attribute tradeoffs on green product preference and choice. Journal of the Academy of Marketing Science, 41(2), 171-184.

Papies, D., Eggers, F., \& Wlomert, N. (2011). Music for free? How free ad-funded downloads affect consumer choice. Journal of the Academy of Marketing Science, 39(5), 777-794.

Pappu, R., \& Cornwell, B. (2014). Corporate sponsorship as an image platform: understanding the roles of relationship fit and sponsorsponsee similarity. Journal of the Academy of Marketing Science, 42(5), 490-510.

Scheer, L., \& Miao, C. (2010). The effects of supplier capabilities on industrial customers' loyalty: the role of dependence. Journal of the Academy of Marketing Science, 38(1), 90-104.

Thompson, S. A., Gooner, R. A., \& Kim, A. (2015). Your mileage may vary: managing untargeted consumers' reactions to promotions. Journal of the Academy of Marketing Science, 43(6), 713-729.

Xie, C., Bagozzi, R. P., \& Gronhaug, K. (2015). The role of moral emotions and individual differences in consumer responses to corporate green and non-green actions. Journal of the Academy of Marketing Science, 43(3), 333-356.

Zielke, S., \& Komor, M. (2015). Cross-national differences in price-role orientation and their impact on retail markets. Journal of the Academy of Marketing Science, 43(2), 159-180. 